\title{
Study of the Radiation Flux Distribution in a Parabolic Dish Concentrator
}

\author{
Nidia Aracely Cisneros-Cárdenas ${ }^{1}$, Rafael Cabanillas-López ${ }^{1}$, Ricardo Pérez-Enciso ${ }^{2}$,

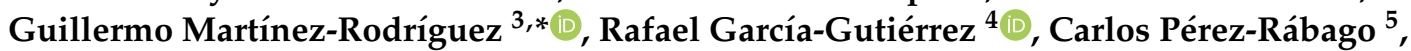 \\ Ramiro Calleja-Valdez ${ }^{1}$ and David Riveros-Rosas ${ }^{6}$ (D)
}

1 Chemical Engineering Department, Universidad de Sonora, Hermosillo 83000, Mexico; a210200645@unison.mx (N.A.C.-C.); rafael.cabanillas@unison.mx (R.C.-L.); ramiro.calleja@unison.mx (R.C.-V.)

2 Industrial Engineering Department, Universidad de Sonora, Hermosillo 83000, Mexico; ricardo.perez@unison.mx

3 Chemical Engineering Department, Universidad de Guanajuato, Guanajuato 36050, Mexico

4 Physics Research Department, Universidad de Sonora, Hermosillo 83000, Mexico; rgarcia@cifus.uson.mx

5 Instituto de Energías Renovables, Universidad Nacional Autónoma de México, Temixco 62580, Mexico; capr@ier.unam.mx

6 Geophysics Institute, Universidad Nacional Autónoma de México, Ciudad de Mexico 04150, Mexico; driveros@igeofisica.unam.mx

* Correspondence: guimarod@ugto.mx

check for updates

Citation: Cisneros-Cárdenas, N.A.; Cabanillas-López, R.; Pérez-Enciso,

R.; Martínez-Rodríguez, G.;

García-Gutiérrez, R.; Pérez-Rábago,

C.; Calleja-Valdez, R.; Riveros-Rosas,

D. Study of the Radiation Flux

Distribution in a Parabolic Dish

Concentrator. Energies 2021, 14, 7053.

https://doi.org/10.3390/en14217053

Academic Editor: Jesús Polo

Received: 28 September 2021

Accepted: 23 October 2021

Published: 28 October 2021

Publisher's Note: MDPI stays neutral with regard to jurisdictional claims in published maps and institutional affiliations.

Copyright: (c) 2021 by the authors. Licensee MDPI, Basel, Switzerland. This article is an open access article distributed under the terms and conditions of the Creative Commons Attribution (CC BY) license (https:// creativecommons.org/licenses/by/ $4.0 /)$.
Abstract: The radiation flux distributions produced by the concentrating solar systems used to produce thermal/electrical power are usually non-homogeneous. This results in non-uniform temperature distributions on the solar receivers, causing adverse effects on the system's overall performance. An approach to better understand the problem is to study the surfaces around the focal zone where the radiation density is homogeneous (isosurfaces), generating them from experimental data. For this, it is necessary to superimpose built volumes of the different irradiance levels using parallel planes in different directions from the focal point of a concentrator. These volumes are known as effective volumes. This study presents the model used to generate effective volume produced by a point focus concentrator, comparing it with experimental results in a direction perpendicular to the focal axis. The effective volumes were developed considering a global optical error of the system of $2.8 \mathrm{mrad}$. The set of methods used to generate effective volumes has not been previously presented in the literature. The theoretical-experimental research consisted of the combination of the camera-target method and the simulations by the ray-tracing technique. The results showed effective volumes with the highest value of $10 \mathrm{MW} / \mathrm{m}^{2}$ and the lowest value of $4.5 \mathrm{MW} / \mathrm{m}^{2}$.

Keywords: solar flux distribution; concentrating solar system; radiation effective volume

\section{Introduction}

Solar energy can be used as a renewable heat source for different processes, such as solar fuels production, electricity, and process heat. These are among the most important in solar energy due to the development of technology and the production of electricity used in various applications, such as buildings, mobility, and manufacturing [1]. The concentrated solar irradiance allows achieving a high energy density to carry out these processes. The technologies that concentrate the irradiance imply lenses or mirrors that redirect the solar rays to an area smaller than the receiving area. The difference between these technologies is their concentrating process, for example, the parabolic dish, parabolic trough, linear fresnel reflector, central tower, and solar furnace [2]. However, the transformation of concentrated solar radiation into thermal power is a considerable challenge that has been solved using a solar receiver [1]. 
The solar irradiance distribution produced by solar concentrating systems is usually non-uniform, which causes a non-uniform temperature distribution in the receiver, causing damage to the material and affecting the heat transfer process, as well as the performance of the system [3]. The solar irradiance distribution depends on the technology and optical configuration to produce concentrated solar radiation. Therefore, studying irradiance distributions will allow us to better understand the problem by determining a volume around the focal zone where the radiation density is uniform; this volume is known as an isosurface [4], but does not provide a solution to achieve an almost homogeneous flux. The effective volume is built by connecting and interpolating 2D irradiance distribution images obtained in successive adjacent planes. The superimposition of the set of effective volumes obtained in different directions around the focal axis will build an isosurface. Irradiance flux depends on the position and the direction of the plane used for the calculation, so an effective volume will not present a uniform distribution flux, as the radiation along the tangential and horizontal planes will have different values $[4,5]$.

Effective volumes refer to empty volumes created from equal intensities of irradiance distribution obtained from irradiance distributions received on parallel flat surfaces along one direction from the optical axis. It is the generation of three-dimensional images from two-dimensional planes scanned in one direction (some authors named this volume the protosurface [4-6]). Therefore, it is possible to calculate the information between the bidimensional planes by interpolation, and all those points will correspond to the same irradiance level. By changing the direction in which planes are scanned, due to slight deviation from the optical axis of the concentrating system, another set of effective volumes is generated.

Experimental methods, such as indirect and direct, and measurement-supported simulation methods have been described in the literature to reveal the radiative flux distribution produced by a concentrating solar system obtaining acceptable results. The simulationbased techniques can provide more information about solar flux maps though it only serves to validate. These simulation-based methods use mathematical procedures to predict the result of the radiative process performed by the concentrating solar system. These mathematical procedures (Ray tracing simulation), based on different methods, such as Simple Ray Tracing, Convolution Ray Tracing, and Monte Carlo Ray Tracing [4,5], have been combined with solar simulators, showing acceptable results [6]. While direct methods use a flux sensor that provides information about the irradiative flux, indirect methods use digital cameras to measure the solar radiation reflected on a diffuse surface [7]. These methods have been used for evaluating $R \& D$ projects on concentrating solar systems to reveal the irradiance distribution in bidimensional planes. Previous studies reveal an irradiance distribution in volumetric receivers but not generating a uniform radiative flux volume through the application of the MCRT method, where the source of the concentrated solar radiation considered is a point focus concentrator [3,8-11].

Du et al. [12] reported a combined technique of X-ray-computed tomography to rebuild a realistic porous absorber with the MCRT to obtain the distribution of radiative flux that is closest to reality; this is not an irradiance distribution provided by the concentrating system itself. At the same time, Ali et al. made theoretical assumptions to simulate the operating conditions of the receiver [1]. Eccher et al. [13] compared the experimental concentrated solar radiation spot and one obtained by simulation without making any variation to the global optical error. The concentrating system, in this case, is a parabolic concentrator. The difference between the spots is attributed to the imperfections and deviations of the concentrator design due to the manufacturing process, again without determining the value of the global optical error and without considering the experimental conditions. Wang et al. [14] assumed theoretical values of direct normal irradiance, reflectivity, and the number of rays for simulations. Ray tracing has been validated with reproducible results confirmed by the experiments in concentrators and is widely accepted $[5,15,16]$.

Riveros-Rosas et al. [4] reported the generation of isosurfaces produced by different concentrating systems, such as a parabolic dish, a rectangular plate with parabolic curva- 
ture, and a concentrator of spherical facet with a parabolic profile, by applying a numerical model varying the optical error of the mirrors. At the same time, Perez-Enciso et al. [5] reported the validation of effective volumes generated by a solar furnace and those experimentally obtained with an established optical error of the mirror, obtaining consistent results.

In summary, theoretical and experimental methods have been described in the literature to obtain the irradiance distribution produced by concentrating solar systems and the irradiance distribution obtained in volumetric receivers. However, the generation of effective volumes from theoretical-experimental methodologies for parabolic dish collectors to determine homogeneous irradiance distributions has not been reported in the literature.

This study aims to reveal the irradiance flux distribution produced by the second surface parabolic dish concentrating system (Figure 1), developed and built by researchers at the University of Arizona [17], to produce electricity using high-efficiency photovoltaic cells. According to the literature, this type of concentrating technology presents extremely non-uniform radiation distribution $[15,16,18]$, thus its study is important. In this study, a validation of a numerical model to build effective volumes and compare with those built from experimental data is presented. The construction of effective volumes in the direction perpendicular to the focal axis of the concentrating system is the first step in generating an isosurface. An isosurface might help to reduce flux peaks and assist in designing a special receiver for this concentrating solar system.

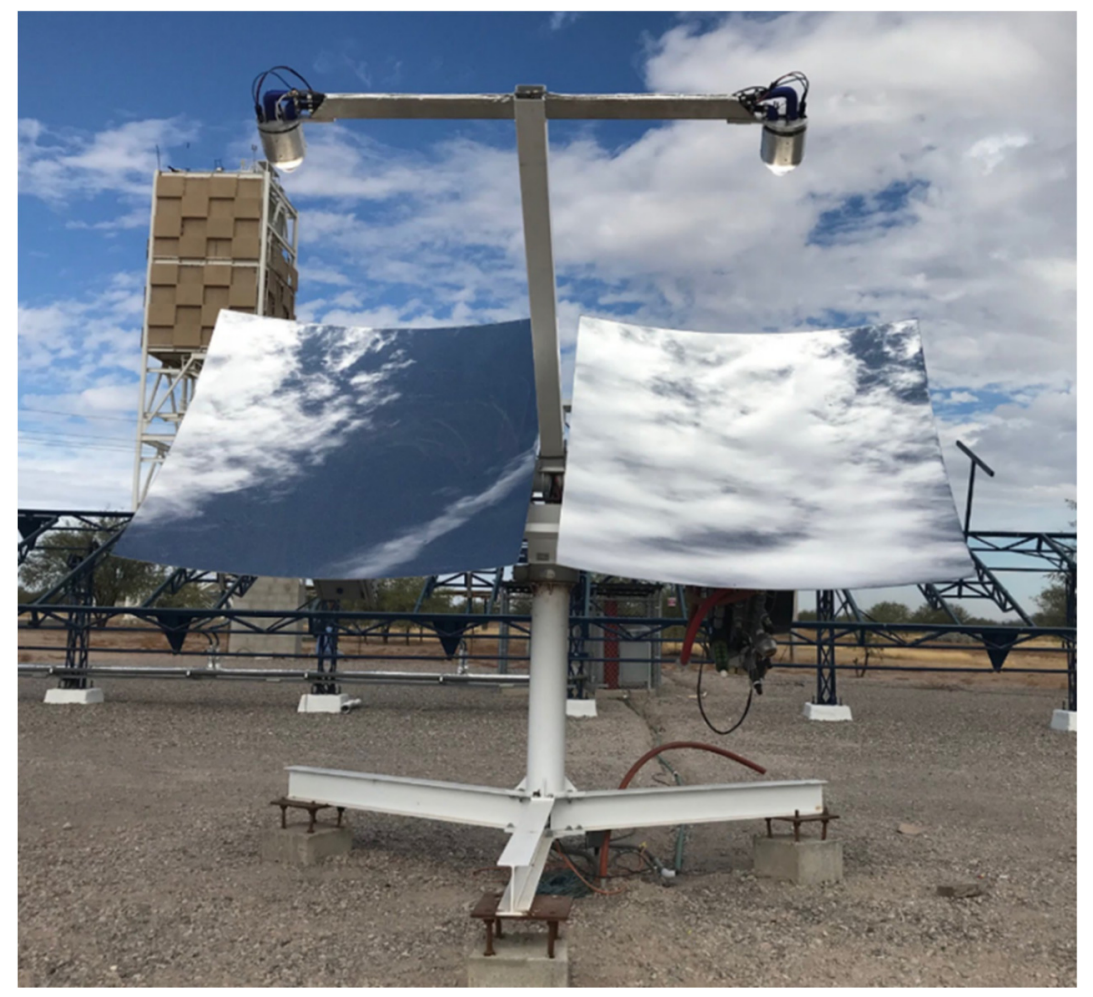

Figure 1. Parabolic Dish Concentrating Solar System located at the Solar Platform of Hermosillo in Hermosillo, Sonora, Mexico.

From this study, cylinders with regular edges are expected as effective volumes because of the geometry of the concentrating mirror. Nevertheless, and according to the literature, the presence of errors in the surfaces could generate a type of optical anomaly and is likely to be aggravated by other factors, such as mechanical efforts produced by gravity and the support of the mirror, thermal efforts from the environmental temperature, the inclination of the optical system, and wind speed and direction [19]. 


\section{Methodology}

This theoretical-experimental study aims to generate the effective volumes produced by a point-focus concentrating system, whose physical characteristics are described in Table 1. Before generating effective volumes, it is necessary to estimate the global optical error of the concentrating system considering the operating conditions, which are different from (controlled) the laboratory conditions. This part is explained in Section 2.4.

The section below describes the experimental set used to scan the images to determine the optical error and the effective volumes generation. After this, the ray-tracing simulation is described, and the effective volumes generation process is presented.

Table 1. Physical Parameters for the Ray Tracing Simulation.

\begin{tabular}{ccc}
\hline & $\begin{array}{c}\text { Parabolic Dish } \\
\text { Concentrator }\end{array}$ & RLFP \\
\hline Measurements & $1.65 \times 1.65 \mathrm{~m}^{2}$ & $0.15 \times 0.25 \mathrm{~m}^{2}$ \\
Focal point & $1.5 \mathrm{~m}$ & - \\
Reflectivity & $0.9^{1}$ & 0 \\
Global optical error of the system & TBD & - \\
Distance from the vertex & - & $1.5 \mathrm{~m}$ \\
\hline
\end{tabular}

${ }^{1}$ This value was provided by the technical data sheet of the parabolic dish concentrator.

\subsection{Experimental Set}

The Camera-Target Method (CTM) is an indirect method since its result only describes the irradiance distribution profiles but not their values. It is also considered a low-cost method to obtain basic optical parameters [20]. CTM uses a charge-coupled device (CCD) camera that records the radiative flux brightness distribution on a diffuse surface located perpendicularly to the optical axis of the parabola at different distances. In addition, the intensity of the concentrated radiation reflected by the parabolic dish was calibrated using a circular radiometer, which is considered a direct method. The advantages of the CTM are fast measurements and high spatial resolution and reliability [7]. Therefore, this method has been used in several projects to evaluate optical systems since the 1970s [5,16,18,20-27]. In addition, the diffuse surface has a diffuse reflection feature, meaning that regardless of the incident angle of radiation, this type of surface reflects in all directions.

A Pike Technologies 8 bits 210 CCD camera (Figure 2a) was used (Fitchburg, WI, USA), to which a filter with linear response to light intensity was adapted. The camera's dynamic range must be set at the highest flux intensity and kept constant during the experiment. This camera was selected due to its linear response to a wide range of intensities and high signal quality. This camera has a matrix of $1920 \times 1080$ pixels, capable of resolving 256 levels of gray.

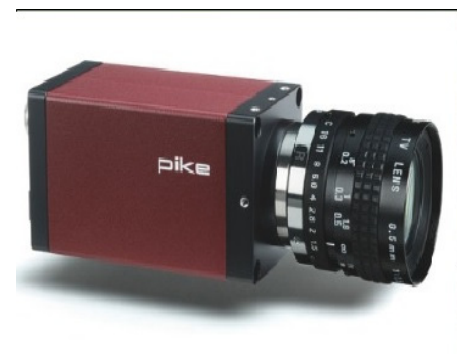

(a)

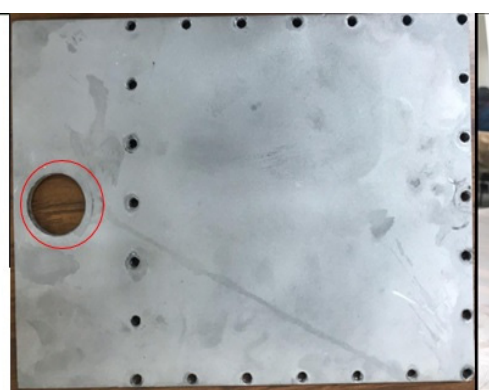

(b)

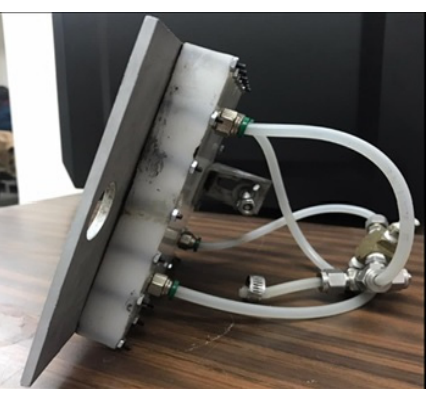

(c)

Figure 2. (a) The 8 bits CCD camera used with a photographic lens and a linear filter, (b) front part of the RLFP (after the experiments) with dimensions of $0.25 \times 0.15 \mathrm{~m}^{2}$, and (c) back of the RLFP where inlets and outlets for coolant flow are shown. 
For this experiment, a Refrigerated Lambertian Flat Plate (RLFP) (Figure 2b) was used, from Instituto de Energías Renovables, Universidad Nacional Autónoma de Mexico, Temixco, Morelos, Mexico. RLFP is made of the junction of an aluminum plate and a nylamid plate. The aluminum plate is subjected to a sandblasting process to achieve a uniform surface and remove any paint residue, grease, and rust. The nylamid plate has inlets and outlets for the coolant flow (Figure 2c). The RLFP was mounted on a linear actuator automatically moved by a control program along the optical axis to facilitate the experiment. To chill the RLFP, two heat exchangers connected in parallel with a total removal capacity of $800 \mathrm{~W}$ and a mass flow of $1 \mathrm{Lpm}$ were required.

The RLFP has an opening where a circular radiometer was placed (Figure 2b) (Vatell Corporation, Christiansburg, VA, USA). Its operation is based on receiving concentrated solar radiation on a thin circular surface of constantan attached to a circular copper block. The energy absorbed by the constantan surface flows radially towards a chilled copper block, acting as a heat reservoir at a constant temperature. As a result of this radial distribution from heat flow, the constantan's surface temperature is higher than the temperature of the copper block. This temperature difference was measured with a thermocouple and could be related through a constant with the radiation intensity [28].

The combination of indirect and direct methods provides enough information to reveal irradiance distribution profiles and their values. Since the concentrating solar system only operates with direct normal irradiance, it must be in the tracking mode, making the procedure difficult because both the concentrating system and RLFP are in motion (Figure 3).

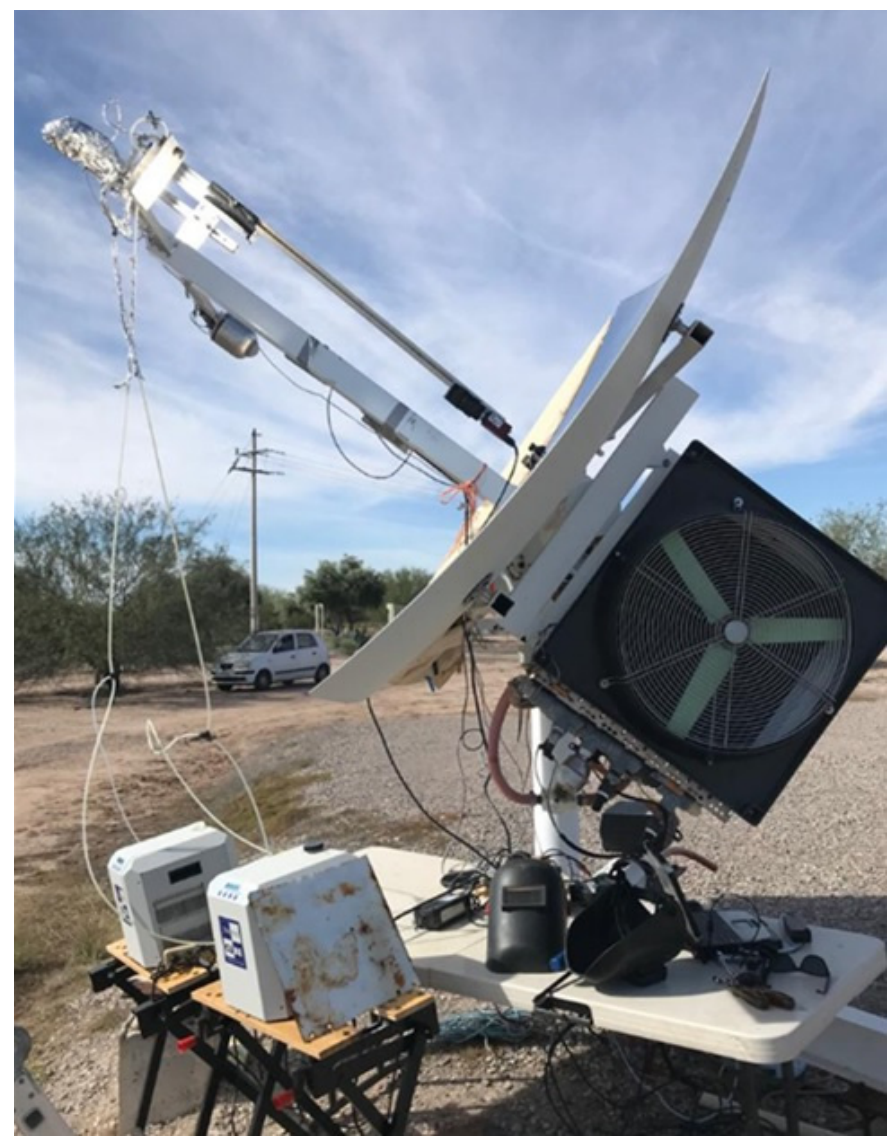

Figure 3. Experimental set mounted on the point-focus concentrator. 


\subsection{Ray Tracing Simulation}

In this study, ray-tracing simulations were performed to characterize the concentrating system, simulating the response behavior of the real system of an event taking place over time [29].

Our approach was based on the Monte Carlo method, which allows mathematical and physical problems to be solved by random variable simulation. The statistical simulation of the radiative transfer phenomenon is based on the emission, reflection, and absorption of the surfaces of the optical system [30]. To carry out the Monte Carlo Ray Tracing simulations, the physical properties of the optical system and the environmental conditions were considered (Figure 4).

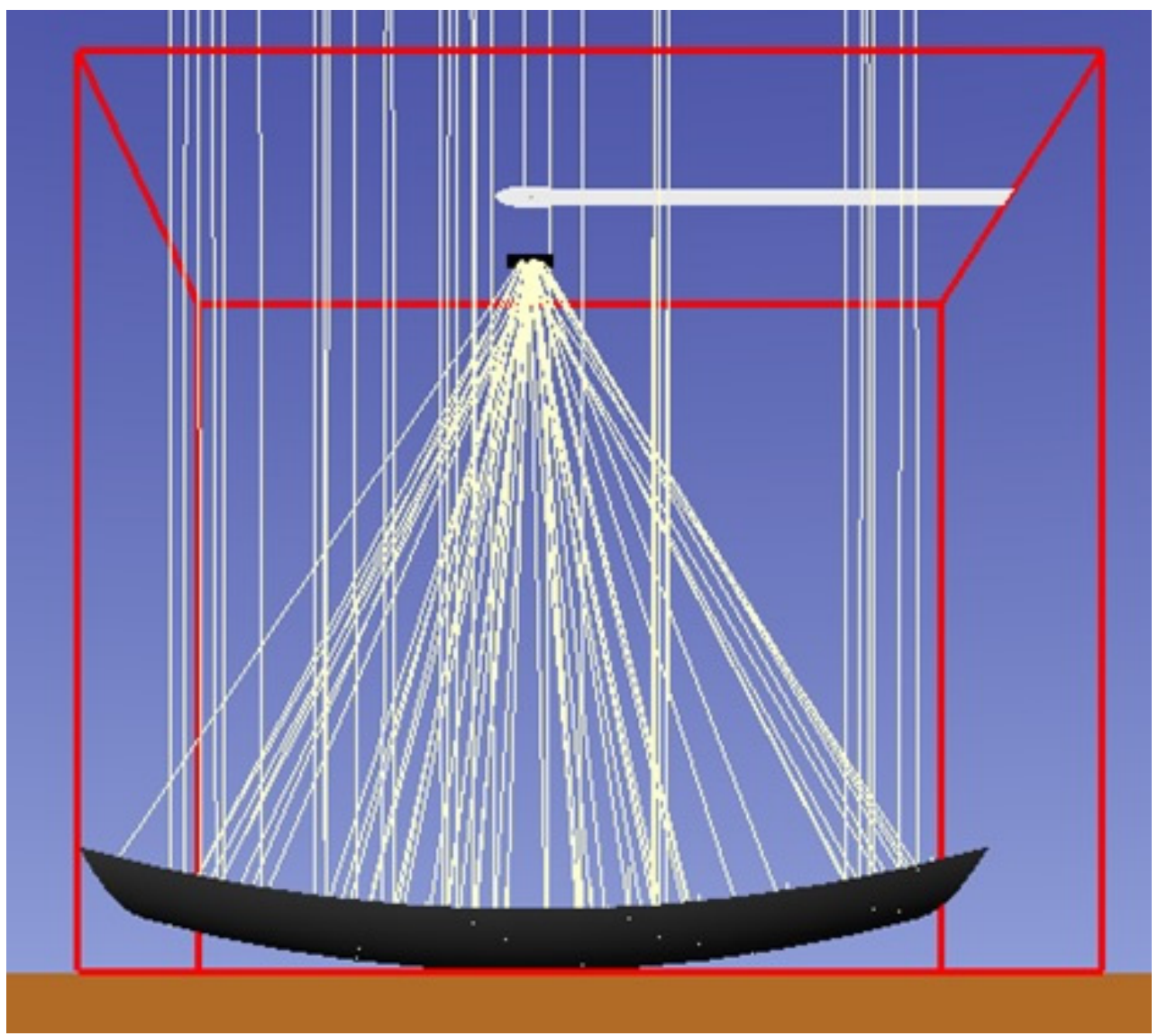

Figure 4. Parabolic dish collector simulated in Tonatiuh.

Tonatiuh v.2.2.4, an optical modeling computer package, was used to carry out the ray-tracing simulation. This free-license software was developed by the National Renewable Energy Center of Spain, in Sarriguren, Navarra, Spain (CENER) and the University of Texas at Brownsville (UTB) with the support of the National Renewable Energy Laboratory (NREL) [31]. The number of rays was established through a ray stability study carried out considering the parameters described in Table 1 , as well as a direct normal irradiance of $1000 \mathrm{~W} / \mathrm{m}^{2}$, a standard sun shape, and a circumsolar ratio value of 0.02 , which were determined experimentally by image analysis of the actual sun (Figure 5). A ray stability study is essential to eliminate the effect of the number of rays for the numerical resolution [32]. Therefore, variation of the maximum power regarding the number of rays was analyzed. The mesh size for the experimental images was $500 \times 500$, and for simulated images was set at $250 \times 250$.

The simulation was carried out considering the receiver was located in the focal zone, and the number of rays varied from 0.01 to 40 million. Considered uncertainty is $4.0 \%$. Table 2 shows that from 5 million rays, uncertainty stays below the set value but has a little 
variation. Twenty million rays was the value selected for the simulations.

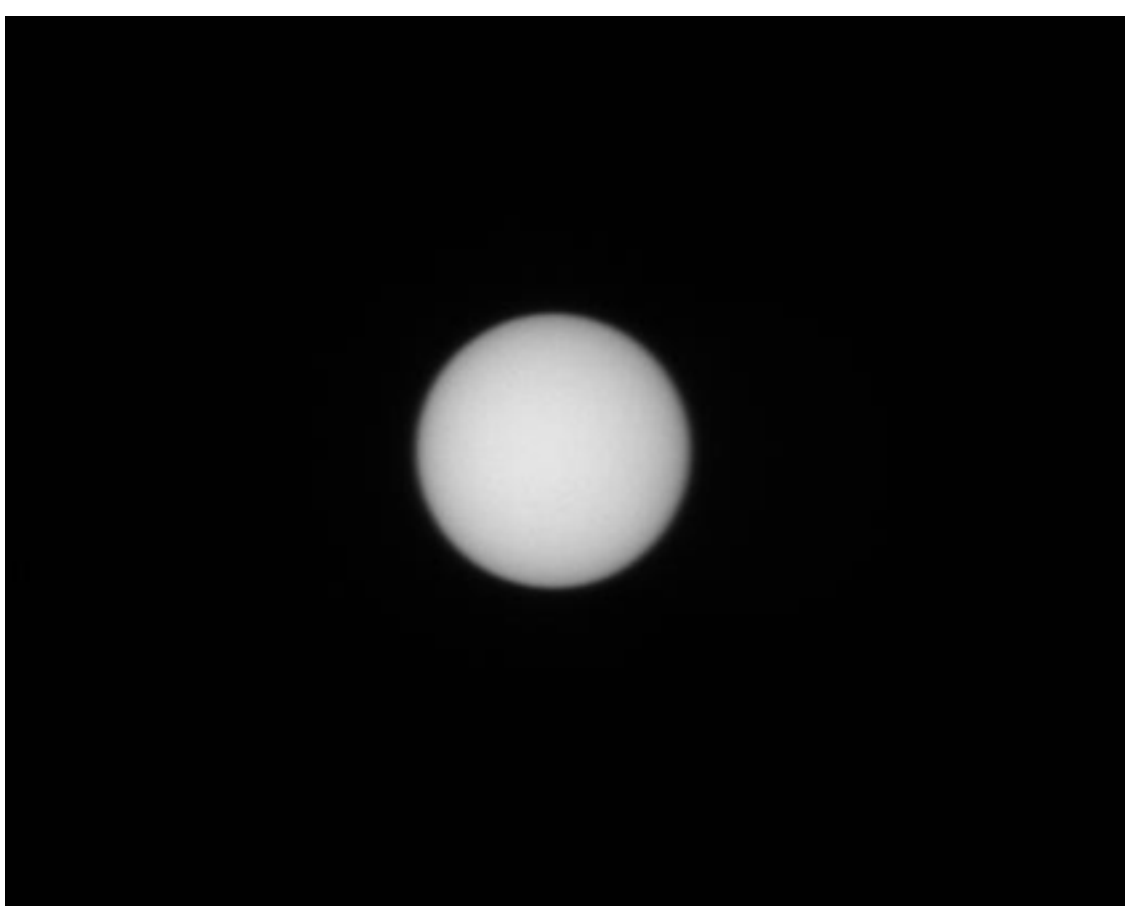

Figure 5. Image of the sun.

Table 2. Ray Independence Study for Ray Tracing Simulation.

\begin{tabular}{ccc}
\hline Numbers of Rays (Millions) & Maximum Power (W) & Uncertainty (\%) \\
\hline 0.01 & $3.36 \times 10^{7}$ & 48.6 \\
0.05 & $1.73 \times 10^{7}$ & 37.5 \\
1 & $1.08 \times 10^{7}$ & 6.5 \\
5 & $1.01 \times 10^{7}$ & 1.5 \\
10 & $9.94 \times 10^{6}$ & -0.5 \\
15 & $9.99 \times 10^{6}$ & 0.2 \\
20 & $9.96 \times 10^{6}$ & 2.2 \\
25 & $9.75 \times 10^{6}$ & -1.1 \\
30 & $9.85 \times 10^{6}$ & 1.1 \\
35 & $9.75 \times 10^{6}$ & 0.5 \\
40 & $9.70 \times 10^{6}$ & -0.5 \\
45 & $9.75 \times 10^{6}$ & \\
\hline
\end{tabular}

The circumsolar ratio, csr, represents the proportion of radiation incidents from the circumsolar region with respect to the total direct irradiance. It results from the scattering of direct sunlight through small angles due to atmospheric molecules and aerosols. Though it could be used as an approximated value [33], if experimental conditions are desired to reproduce in the simulation process, this value must be experimentally determined. A photograph of the solar disc was scanned (Figure 5), with the previously described CCD camera equipped with linear filters allowing an unsaturated image immediately after the application of the CTM to be obtained. After this, the solar irradiance distribution profiles in the center of the scanned image were analyzed and compared to different sun shapes produced by the software-varying csr value. The csr was determined by tying the theoretical value with the experimental one (Figure 6) [34]. 


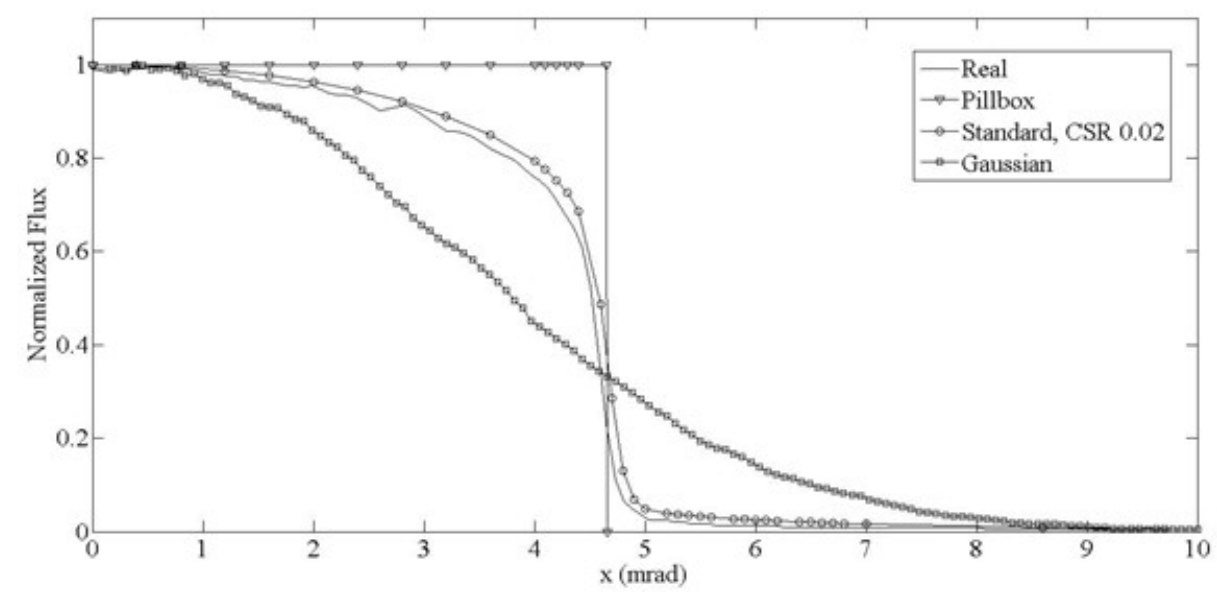

Figure 6. Irradiance profile distribution of the sun.

\subsection{Global Optical Error of the System}

The optical error of the mirror is described by the difference between the diameter of the real sun and the diameter of the degraded sun produced by the concentrator mirror; it can be approximated with a normal distribution.

Microscopic or roughness errors are associated with the substrate material, whereas macroscopic or slope errors cause a deviation in the direction of the reflected cone due to the surface slope errors. The slope deviation duplicates the error angle and is related to the manufacturing process. In summary, the global optical error of a reflective surface is the junction of these microscopic and macroscopic errors and is calculated as shown in Equation (1) [22].

$$
\sigma_{g}=\left(\sigma_{r}^{2}+4 \sigma_{o}^{2}\right)^{0.5}
$$

where $\sigma_{g}$ is the global optical error, $\sigma_{r}$ stands for the roughness error, and $\sigma_{o}$ refers to the slope error. In addition to the optical errors of the concentrator mirror described previously, deviation caused by tracking $\left(\sigma_{\text {track }}\right)$, displacement, control systems, data logger, and sun shape $\left(\sigma_{\text {sun }}\right)$ must be considered as a part of the global optical error of the system. Therefore, Equation (1) must consider these parameters (Equation (2)) [19]. If these parameters are omitted from the formula, the global optical error of the system could be underestimated. Some of these parameters were also affected by non-controlled conditions, such as solar irradiance, environmental temperature, and wind speed and direction.

$$
\sigma_{g}=\left(\sigma_{\text {sun }}^{2}+\sigma_{\text {track }}^{2}+\sigma_{\text {displacement }}^{2}+\sigma_{r}^{2}+4 \sigma_{o}^{2}\right)^{0.5},
$$

The global optical error of the system was calculated by comparing the irradiance distribution profiles from the experimental and theoretical scanned images in the focal zone of the concentrating system, evaluating them in vertical and horizontal axes of the concentrated solar radiation centroid. First, a quantitative approximation was carried out by varying the theoretical optical error around the real error, allowing an approximate error interval to be estimated. Theoretical irradiance distribution profiles were generated, varying the error in the determined interval. The global optical error of the system was estimated when the average difference between the experimental profile and the theoretical one presented the smallest standard deviation. The described method only calculates the global optical error of the system by comparing irradiance distribution profiles, but not by one of the terms described in Equation (2).

\subsection{Generation of Effective Volumes}

To generate the effective volumes, the irradiance distribution images produced by the concentrating system on the RLFP were scanned experimentally. Once the global 
optical error of the system was obtained, the theoretical irradiance distribution images were acquired.

The concentrating system must be in operating mode during the image scanning process. The images were scanned from 1.4 to $1.6 \mathrm{~m}$ from the vertex of the parabola mirror with $0.002 \mathrm{~m}$ between them (Figure 7). A total of 31 bidimensional and parallel planes to the optical axis of the concentrator mirror were scanned. Therefore, information between bidimensional planes is generated by interpolation through commands made in MATLAB 2014a, and the build of three-dimensional images of different irradiance levels is obtained.

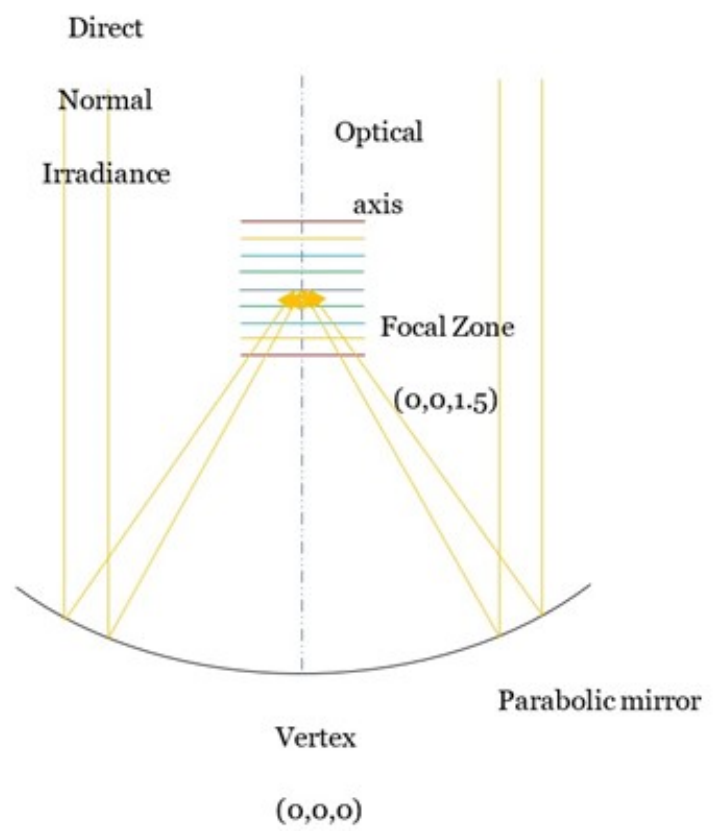

Figure 7. Effective volume generation scheme.

\section{Results and Discussion}

\subsection{Global Optical Error of the System}

The scanned image at the focal zone in the concentrating system is shown in Figure 8a. From this image, irradiance distribution profiles were obtained as shown with red lines. These profiles have a gaussian distribution through the applied methodology described in Section 2.3. The quantitative approximation is set between 2.0 and $3.0 \mathrm{mrad}$ due to the real profile being between these values (Figure 9). The qualitative approximation was determined by varying the error from 2.0 to $3.0 \mathrm{mrad}$ (Figure 10). The global optical error of the system was calculated at $2.8 \mathrm{mrad}$; thus this value presented the lowest standard deviation. The maximum value registered by the circular radiometer was $10 \mathrm{MW} / \mathrm{m}^{2}$.

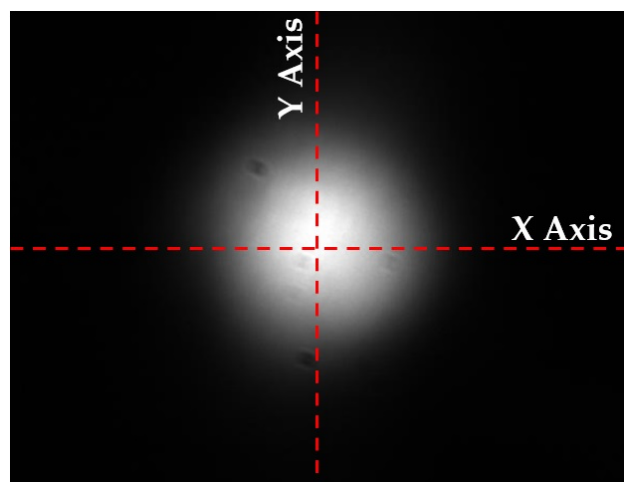

(a)

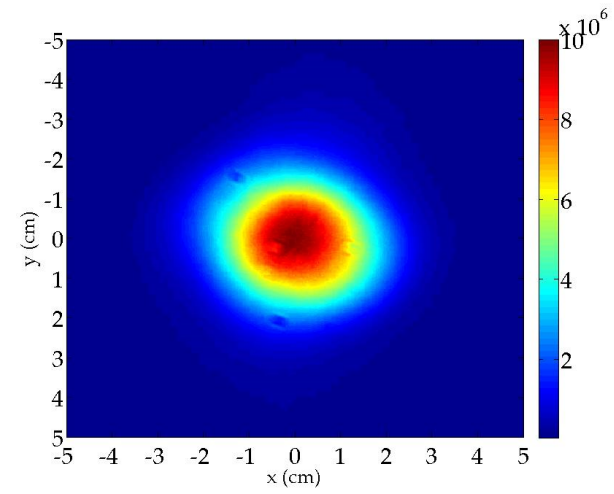

(b)

Figure 8. Real concentrated solar radiation spot in the focal zone: (a) Gray Scale and (b) Real flux values $\left(\mathrm{MW}^{\mathrm{m}} \mathrm{m}^{2}\right)$. 


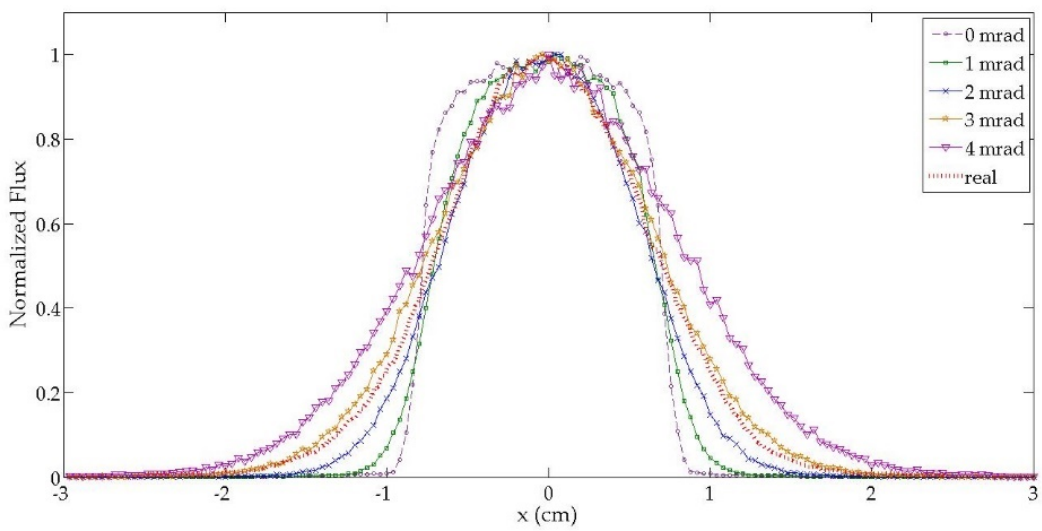

Figure 9. Qualitative matching of the solar radiation distribution profiles (theoretical and experimental) when $x=0, y=[-3.3]$, varying the global optical error from 0 to 4 mrad with increments of $1 \mathrm{mrad}$.

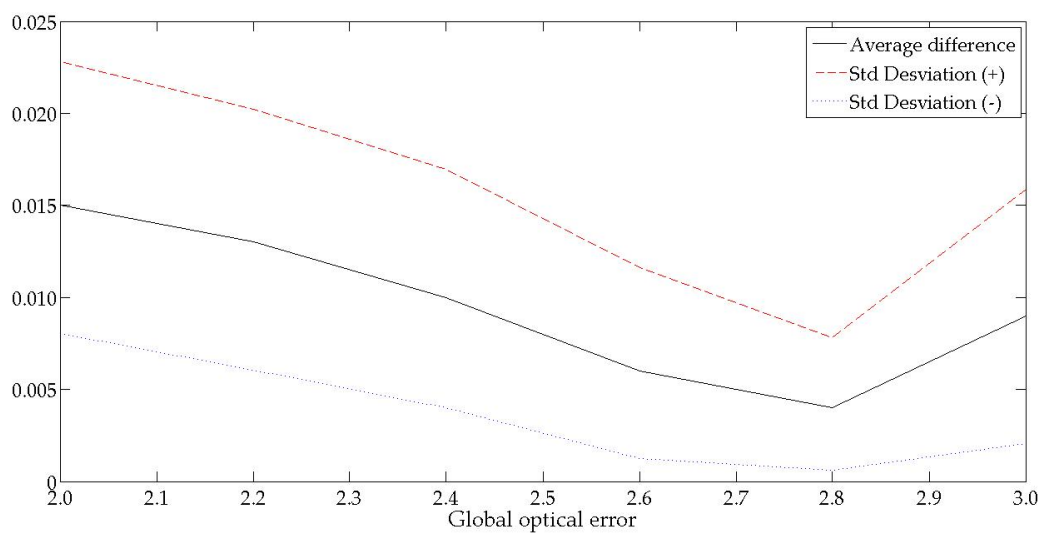

Figure 10. Quantitative comparison of solar radiation distribution profiles varying the error from 2.0 to $3.0 \mathrm{mrad}$.

\subsection{Effective Volumes}

The real and theoretical effective volumes are presented in Figures 11 and 12, respectively. Different uniform irradiance levels are shown, as seen in those figures. It is evident that the higher the flux value, the smaller the surface. For a flux value of $10 \mathrm{MW} / \mathrm{m}^{2}$, theoretical effective volumes present a length in the $z$-axis of $\sim 2 \mathrm{~cm}$ and $1 \mathrm{~cm}$ in the $x$ and $y$ axes, while in experimental ones, lengths of less than $2 \mathrm{~cm}$ in the $z$-axis and $1 \mathrm{~cm}$ in the $x$ and $y$-axes were observed.

Comparing the shapes of theoretical and experimental effective volumes, some differences and trends can be seen.

Considering the shapes of effective volumes, theoretical and experimental types show differences between them. For theoretical effective volumes, higher irradiance levels present oval shapes, which are transformed into a cylinder for decreasing values. For experimental effective volumes, smaller flux presents a twist in the extreme side of the surfaces.

Experimental and theoretical isolines located at the focal zone in the $x y, x z$ and $y z$ planes are shown in Figures 13 and 14, respectively. Both experimental and theoretical $x y$ planes present a circular distribution and are very similar to each other because the images were scanned in this plane, whereas the other planes ( $x z$ and $y z)$ differ from each other. In addition, in Figure 13b,c, the twist can be appreciated at the smaller fluxes, while in Figure $14 \mathrm{~b}, \mathrm{c}$, this is not present. 


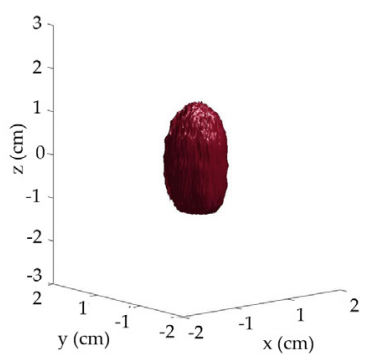

(a)

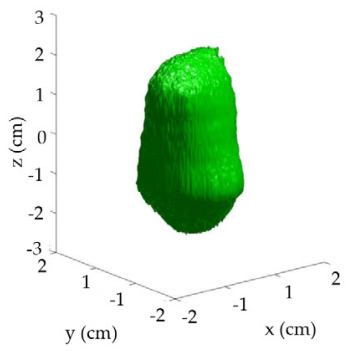

(e)

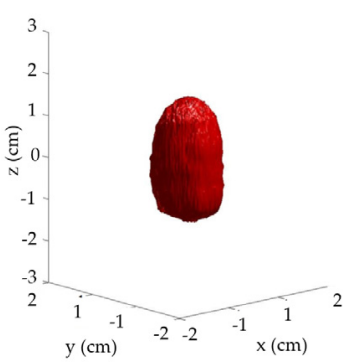

(b)

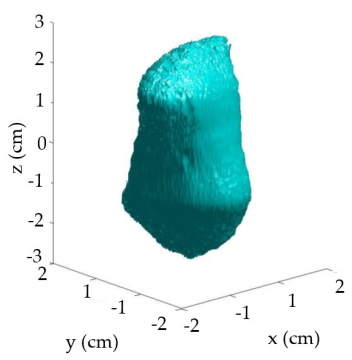

(f)

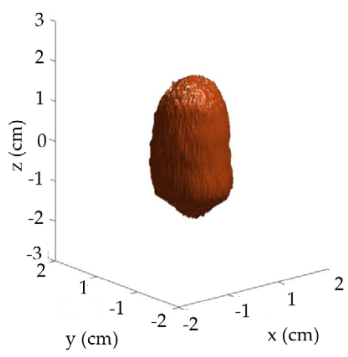

(c)

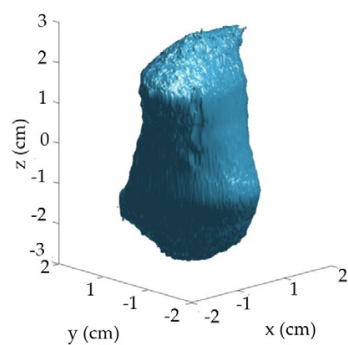

(g)

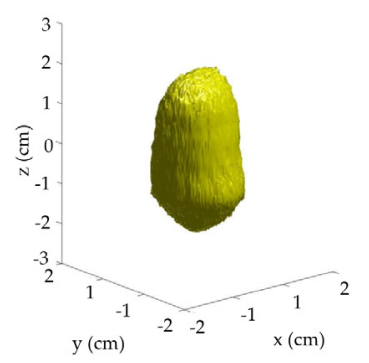

(d)

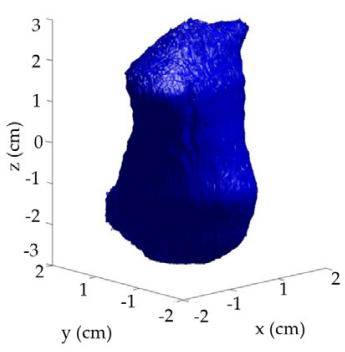

(h)

Figure 11. Experimental effective volumes of different flux values: (a) 10, (b) 9, (c) 8, (d) 7, (e) 6, (f) 5, (g) 4.5, and (h) 4 $\mathrm{MW} / \mathrm{m}^{2}$.

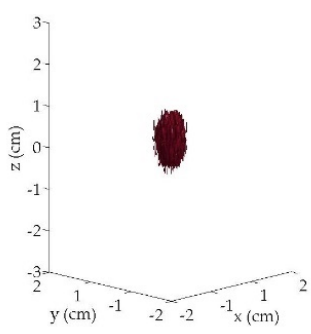

(a)

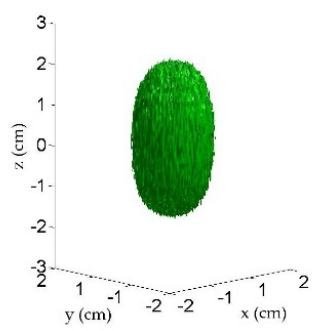

(e)

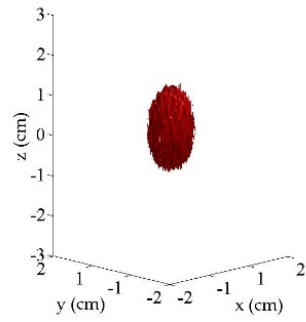

(b)

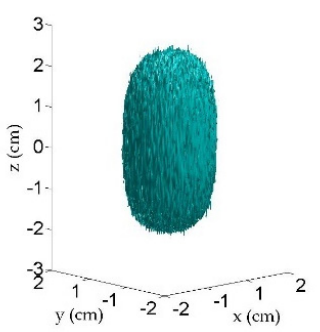

(f)

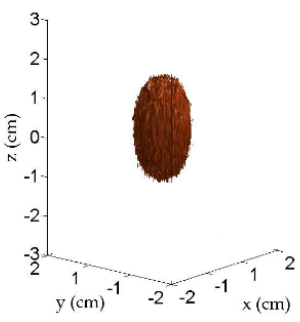

(c)

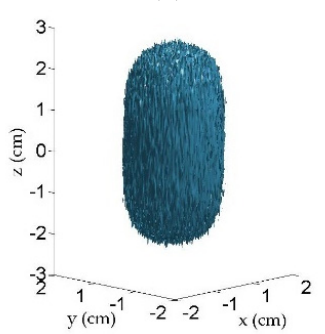

(g)

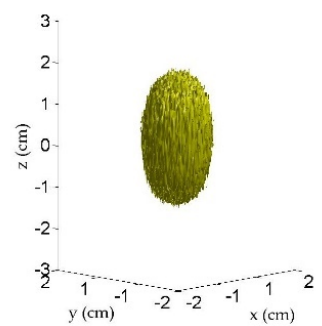

(d)

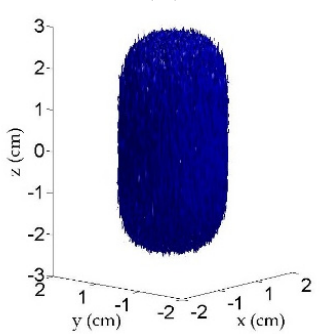

(h)

Figure 12. Theoretical effective volumes of different flux values: (a) 10, (b) 9, (c) 8, (d) 7, (e) 6, (f) 5, (g) 4.5, and (h) $4 \mathrm{MW} / \mathrm{m}^{2}$.

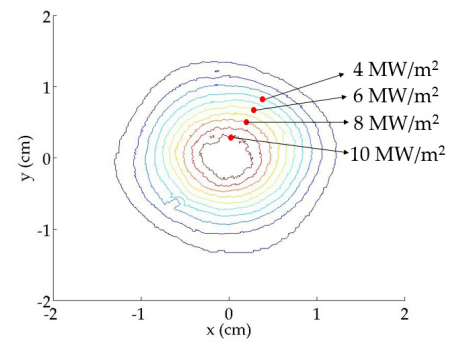

(a)

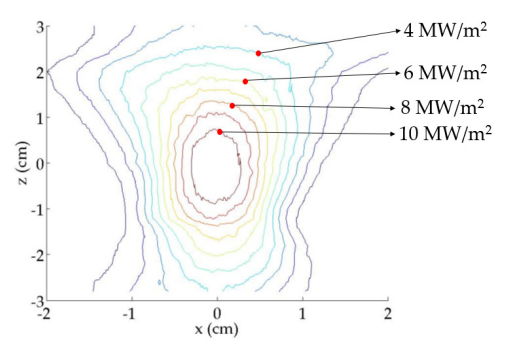

(b)

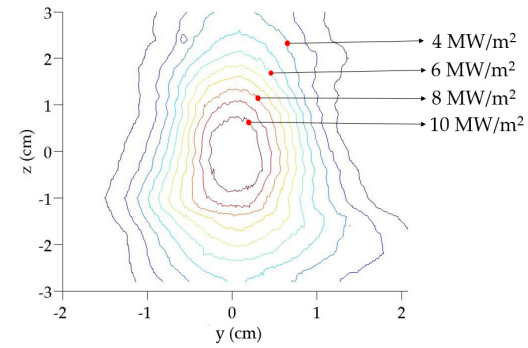

(c)

Figure 13. Experimental isolines in planes (a) $x y$, (b) $x z$, and (c) $y z$. 


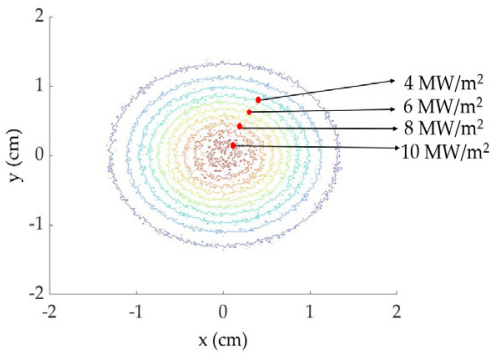

(a)

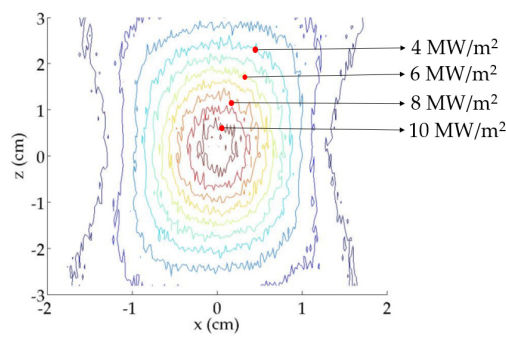

(b)

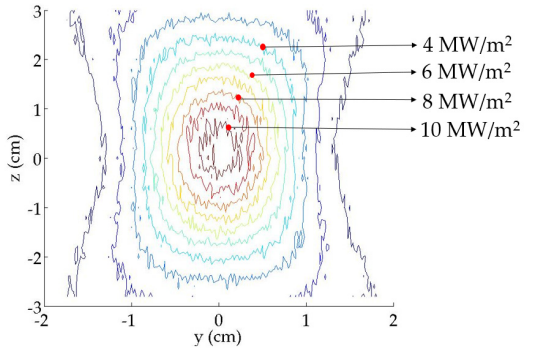

(c)

Figure 14. Theoretical isolines in planes (a) $x y$, (b) $x z$, and (c) yz.

Table 3 presents a quantitative comparison of the isolines shown in the previous figures. Areas from each flux were compared, taking as reference the real area to calculate the difference between them. The results show that theoretical irradiance area values are overestimated, presenting the smallest difference on the $x y$ plane at $10 \mathrm{MW} / \mathrm{m}^{2}$ with $7.6 \%$ and the largest at $4 \mathrm{MW} / \mathrm{m}^{2}$ on the $x z$ plane with $174 \%$.

Table 3. Isolines quantitative comparison.

\begin{tabular}{|c|c|c|c|c|c|c|c|c|c|}
\hline \multirow{2}{*}{$\begin{array}{c}\text { Flux } \\
\left(\mathrm{MW} / \mathrm{m}^{2}\right)\end{array}$} & \multicolumn{3}{|c|}{ XY Plane } & \multicolumn{3}{|c|}{ XZ Plane } & \multicolumn{3}{|c|}{ YZ Plane } \\
\hline & 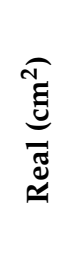 & 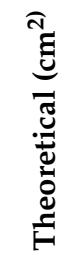 & 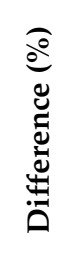 & 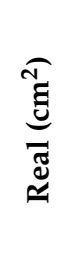 & 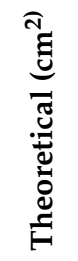 & 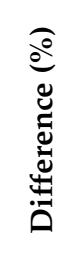 & 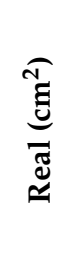 & 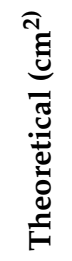 & 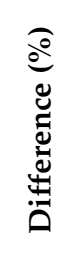 \\
\hline 10 & 0.21 & 0.28 & 7.6 & 0.31 & 0.50 & 18.5 & 0.32 & 0.55 & 22.7 \\
\hline 9 & 0.41 & 0.53 & 12.2 & 0.90 & 0.28 & 28.4 & 0.64 & 0.94 & 29.8 \\
\hline 8 & 0.64 & 0.79 & 14.3 & 0.95 & 1.43 & 48.6 & 0.99 & 1.42 & 43.5 \\
\hline 7 & 0.89 & 1.13 & 24.9 & 1.30 & 1.89 & 58.6 & 1.33 & 2.21 & 88.3 \\
\hline 6 & 1.17 & 1.44 & 27.0 & 1.80 & 2.68 & 88.1 & 1.90 & 2.71 & 80.7 \\
\hline 4 & 1.88 & 2.40 & 52.1 & 3.40 & 5.07 & 167.0 & 3.37 & 5.11 & 174.0 \\
\hline
\end{tabular}

\subsection{Discussion}

The methodology established calculated the global optical error and obtained acceptable results. The optical imaging system evaluated the reproduced image of the sun, including the optical error that degrades the images. This error was calculated as $2.8 \mathrm{mrad}$. This points out the difference in the diameters of the real sun and the degraded sun produced by the system.

The theoretical effective volumes may not be considered as ideal ones due to the global optical error introduced. To build theoretical effective volumes that reproduce the experimental results, previous authors consider that some parameters used for simulation might be changed. Varying the focal length of the axes ( $x$ and $y)$ could help reproduce the twist seen in the extreme sides of the experimental effective volumes. This twist could be due to mechanical efforts, thermal efforts, or wind speed and direction. However, determining the origin of this discovery is beyond the scope of this work.

The global optical error was determined on the $x y$ plane. This explains the smallest difference comparing the theoretical and experimental isolines presented in this plane.

The low flux effective volumes are difficult to model because of the different sources of errors. These sources of errors are non-homogeneous and draw back from the gaussian distribution of the errors. 


\section{Conclusions}

A novel theoretical-experimental methodology has been established to calculate the global optical error of the system and to generate different irradiance level surfaces produced by a parabolic dish concentrating system. These effective volumes obtained in the direction perpendicular to the focal axis are the first step in building uniform irradiance distribution surfaces. This helps reduce the peaks flux in the solar receivers, thus improving the performance of the overall system. To generate isosurfaces produced by this concentrating system, experimental and theoretical data must be collected in successive parallel planes, along several different directions, they must be superimposed to create an isosurface.

Several difficulties were presented during the development of the experimental methodology caused by the motion of the concentrating solar system, which must be due to the operating mode of scanning the images, as well as the cooling system, making the process difficult.

In contrast to previous studies, the experimental effective volumes were generated considering a global optical error of the system revealed at $2.8 \mathrm{mrad}$ under operating conditions; this considers errors of the concentrating mirror, tracking system, control system, sun shape, and circumsolar ratio. In addition, theoretical effective volumes were generated from the established error, and a qualitative and quantitative comparison was made through isolines.

Differences between theoretical and real effective volumes were found, both in shape and dimensions. The highest flux revealed was $10 \mathrm{MW} / \mathrm{m}^{2}$, and the lowest was $4.5 \mathrm{MW} / \mathrm{m}^{2}$. Higher flux theoretical effective volumes presented an oval shape; by decreasing the flux value, they are transformed into an ellipsoid. Higher flux experimental effective volumes also presented oval shapes by decreasing the flux value, a twist in the extreme sides was observed. This twist could be due to mechanical efforts, thermal efforts, or wind direction and speed; however, determining the origin is not important for this work because the determination of the global optical error of the system is done in the focal zone-highintensity region-whereas this error might not be revealed at low-intensity regions.

Author Contributions: Conceptualization, R.P.-E., G.M.-R., R.G.-G., and C.P.-R.; Formal analysis, N.A.C.-C., R.P.-E., and C.P.-R.; Funding acquisition, G.M.-R.; Investigation, N.A.C.-C.; Methodology, N.A.C.-C., R.C.-L., R.P.-E., C.P.-R., R.C.-V., and D.R.-R.; Writing-original draft, N.A.C.-C.; Writingreview and editing, G.M.-R., R.G.-G., and D.R.-R. All authors have read and agreed to the published version of the manuscript.

Funding: This research was funded by CONACYT-Mexico, project 316058, year 2021.

Data Availability Statement: Data sharing is not applicable to this article.

Acknowledgments: Special thanks to the technical and administrative personnel of the Solar Platform of Hermosillo.

Conflicts of Interest: The authors declare no conflict of interest. The funders had no role in the design of the study; in the collection, analyses, or interpretation of data; in the writing of the manuscript, or in the decision to publish the results.

\section{References}

1. Ali, M.; Rady, M.; Attia, M.A.A.; Ewais, E.M.M. Consistent coupled optical and thermal analysis of volumetric solar receivers with honeycomb absorbers. Renew. Energy 2020, 145, 1849-1861. [CrossRef]

2. Raboaca, M.S.; Badea, G.; Enache, A.; Filote, C.; Rasoi, G.; Rata, M.; Lavric, A.; Felseghi, R.A. Concentrating solar power technologies. Energies 2019, 12, 1048. [CrossRef]

3. Wang, F.; Shuai, Y.; Tan, H.; Zhang, X.; Mao, Q. Heat transfer analyses of porous media receiver with multi-dish collector by coupling MCRT and FVM method. Sol. Energy 2013, 93, 158-168. [CrossRef]

4. Riveros-Rosas, D.; Sánchez-González, M.; Estrada, C.A. Three-dimensional analysis of a concentrated solar flux. J. Sol. Energy Eng. Trans. ASME 2008, 130, 0145031-0145034. [CrossRef] 
5. Perez-Enciso, R.; Riveros-Rosas, D.; Sanchez, M.; Pérez-Rabago, C.A.; Arancibia-Bulnes, C.A.; Romero-Paredes, H.; Estrada, C.A. Three-dimensional analysis of solar radiation distribution at the focal zone of the solar furnace of IER-UNAM. Energy Procedia 2014, 57, 3031-3040. [CrossRef]

6. Gómez, F.; Gonzalez-aguilar, J.; Romero, M. Experimental 3D flux distribution of a 7 kW e-solar simulator. In Proceedings of the 17th SolarPACES Conference, Granada, Spain, 20 September 2011.

7. Röger, M.; Herrmann, P.; Ulmer, S.; Ebert, M.; Prahl, C.; Göhring, F. Techniques to measure solar flux density distribution on large-scale receivers. J. Sol. Energy Eng. Trans. ASME 2014, 136, 1-10. [CrossRef]

8. Chen, X.; Xia, X.; Liu, H.; Li, Y.; Liu, B. Heat transfer analysis of a volumetric solar receiver by coupling the solar radiation transport and internal heat transfer. Energy Convers. Manag. 2016, 114, 20-27. [CrossRef]

9. Barreto, G.; Canhoto, P.; Collares-Pereira, M. Three-dimensional modelling and analysis of solar radiation absorption in porous volumetric receivers. Appl. Energy 2018, 215, 602-614. [CrossRef]

10. Chen, X.; Xia, X.L.; Dong, X.H.; Dai, G.L. Integrated analysis on the volumetric absorption characteristics and optical performance for a porous media receiver. Energy Convers. Manag. 2015, 105, 562-569. [CrossRef]

11. Wang, F.; Shuai, Y.; Tan, H.; Yu, C. Thermal performance analysis of porous media receiver with concentrated solar irradiation. Int. J. Heat Mass Transf. 2013, 62, 247-254. [CrossRef]

12. Du, S.; Li, M.J.; Ren, Q.; Liang, Q.; He, Y.L. Pore-scale numerical simulation of fully coupled heat transfer process in porous volumetric solar receiver. Energy 2017, 140, 1267-1275. [CrossRef]

13. Eccher, M.; Turrini, S.; Salemi, A.; Bettonte, M.; Miotello, A.; Brusa, R.S. Construction method and optical characterization of parabolic solar modules for concentration systems. Sol. Energy 2013, 94, 19-27. [CrossRef]

14. Wang, G.; Wang, F.; Shen, F.; Jiang, T.; Chen, Z.; Hu, P. Experimental and optical performances of a solar CPV device using a linear Fresnel reflector concentrator. Renew. Energy 2020, 146, 2351-2361. [CrossRef]

15. He, Y.L.; Wang, K.; Qiu, Y.; Du, B.C.; Liang, Q.; Du, S. Review of the solar flux distribution in concentrated solar power: Non-uniform features, challenges, and solutions. Appl. Therm. Eng. 2019, 149, 448-474. [CrossRef]

16. Xia, X.L.; Dai, G.L.; Shuai, Y. Experimental and numerical investigation on solar concentrating characteristics of a sixteen-dish concentrator. Int. J. Hydrogen Energy 2012, 37, 18694-18703. [CrossRef]

17. Coughenour, B.M.; Stalcup, T.; Wheelwright, B.; Geary, A.; Hammer, K.; Angel, R. Dish-based high concentration PV system with Köhler optics. Opt. Express 2014, 22, A211. [CrossRef] [PubMed]

18. Johnston, G. Focal region measurements of the $20 \mathrm{~m}^{2}$ tiled dish at the Australian National University. Sol. Energy 1998, 63, 117-124. [CrossRef]

19. Güven, H.M.; Bannerot, R.B. Derivation of universal error parameters for comprehensive optical analysis of parabolic troughs. J. Sol. Energy Eng. Trans. ASME 1986, 108, 275-281. [CrossRef]

20. Ulmer, S.; Reinalter, W.; Heller, P.; Lüpfert, E.; Martínez, D. Beam characterization and improvement with a flux mapping system for dish concentrators. J. Sol. Energy Eng. Trans. ASME 2002, 124, 182-188. [CrossRef]

21. Qiu, K.; Yan, L.; Ni, M.; Wang, C.; Xiao, G.; Luo, Z.; Cen, K. Simulation and experimental study of an air tube-cavity solar receiver. Energy Convers. Manag. 2015, 103, 847-858. [CrossRef]

22. Shuai, Y.; Xia, X.; Tan, H. Numerical simulation and experiment research of radiation performance in a dish solar collector system. Front. Energy Power Eng. China 2010, 4, 488-495. [CrossRef]

23. Jaramillo, O.A.; Pérez-Rábago, C.A.; Arancibia-Bulnes, C.A.; Estrada, C.A. A flat-plate calorimeter for concentrated solar flux evaluation. Renew. Energy 2008, 33, 2322-2328. [CrossRef]

24. Dähler, F.; Wild, M.; Schäppi, R.; Haueter, P.; Cooper, T.; Good, P.; Larrea, C.; Schmitz, M.; Furler, P.; Steinfeld, A. Optical design and experimental characterization of a solar concentrating dish system for fuel production via thermochemical redox cycles. Sol. Energy 2018, 170, 568-575. [CrossRef]

25. Perez-Enciso, R.; Gallo, A.; Riveros-Rosas, D.; Fuentealba-Vidal, E.; Perez-Rábago, C. A simple method to achieve a uniform flux distribution in a multi-faceted point focus concentrator. Renew. Energy 2016, 93, 115-124. [CrossRef]

26. Lovegrove, K.; Burgess, G.; Pye, J. A new $500 \mathrm{~m}^{2}$ paraboloidal dish solar concentrator. Sol. Energy 2011, 85, 620-626. [CrossRef]

27. Biryukov, S. Determining the optical properties of PETAL, the $400 \mathrm{~m}^{2}$ parabolic dish at Sede Boqer. J. Sol. Energy Eng. Trans. ASME 2004, 126, 827-832. [CrossRef]

28. Gardon, R. An instrument for the direct measurement of intense thermal radiation. Rev. Sci. Instrum. 1953, 24, 366-370. [CrossRef]

29. Shannon, R.E. 1998_0002.pdf. In Proceedings of the 1998 Winter Simulation Conference, Washington, DC, USA, 13-16 December 1998; pp. 7-14.

30. Shuai, Y.; Xia, X.L.; Tan, H.P. Numerical study of radiation characteristics in a dish solar collector system. J. Sol. Energy Eng. Trans. ASME 2008, 130, 0210011-0210018. [CrossRef]

31. Blanco, M.J.; Amieva, J.M.; Mancillas, A. The Tonatiuh Software Development Project: An Open Source Approach to the Simulation of Solar Concentrating Systems. In Proceedings of the Computers and Information in Engineering, Orlando, FL, USA, 5-11 November 2005; ASMEDC: Orlando, FL, USA, 2005; pp. 157-164.

32. Lokeswaran, S.; Mallick, T.K.; Reddy, K.S. Design and analysis of dense array CPV receiver for square parabolic dish system with CPC array as secondary concentrator. Sol. Energy 2020, 199, 782-795. [CrossRef] 
33. Neumann, A.; Groer, U. Experimenting with concentrated sunlight using the DLR solar furnace. Sol. Energy 1996, 58, 181-190. [CrossRef]

34. Neumann, A.; Witzke, A.; Jones, S.A.; Schmitt, G. Representative terrestrial solar brightness profiles. J. Sol. Energy Eng. Trans. ASME 2002, 124, 198-204. [CrossRef] 